\title{
A SURVEY ON THE ADOPTION OF GIS DATA AND STANDARDS IN URBAN APPLICATION DOMAINS
}

\author{
Kavisha Kumar, Anna Labetski, Giorgio Agugiaro, Jantien Stoter \\ 3D Geoinformation, Delft University of Technology, The Netherlands \\ \{k.kavisha, a.labetski, g.agugiaro, j.e.stoter\}@tudelft.nl
}

Commission IV, WG IV/10

KEY WORDS: GIS, Standards, 2D, 3D, City Models

\begin{abstract}
:
GIS has become an important part of many disciplines and supports a vast range of applications. It is used everywhere, from agriculture to public health care. Furthermore, with the advances in technologies, the availability of GIS data and software support has grown exponentially. In this paper, we present the results of our international survey to investigate the adoption of geospatial data, standards, and software by the practitioners in different application domains. The results demonstrate a clear trend towards the increased use of GIS in a number of application domains including architecture, geosciences, hydrology, and so on. We also explore the expectations of the users from the GIS technologies and provide some insight into the current status of 3D GIS data and its applications.
\end{abstract}

\section{INTRODUCTION}

The field of GIS (Geographic Information Systems) is constantly changing and evolving. Over the course of the last two decades, the GIS community has seen software technology advance from command line, workstation-based tools to software that can now be used on mobile devices and in the cloud. Nowadays, GIS is used everywhere, from agriculture to public health care. Simultaneously, the availability of geodata has grown exponentially, thanks to advances in the different technologies, at different geographical scales, used to acquire data (e.g. satellites, drones, and sensors, just to name a few). Furthermore, there is a growing trend to make geodata publicly available, in order to foster development of new and innovative applications. GIS standards are essential for harmonising the technical specifications to aid in the usability of this data for developers, stakeholders, and other users.

With the growing number of standards and availability of (open) GIS data, we undertook this initiative to explore how practitioners in different GIS domains make use of spatial data, standards, and software. There are many studies exploring the status of GIS in the field of archaeology (De Roo et al., 2013), public health (Bissette et al., 2009), urban planning (Göçmen et al., 2010), education (Kerski, 1999), and user requirements analysis (for 3D data) (Wong, 2015), to name a few. However, none of these studies compare the results across different urban application domains.

Our study adopted a user-oriented approach to understand how geospatial data is used in different urban application domains. We designed and distributed a web-based survey to investigate the adoption of geospatial data, standards, and software by the practitioners, and received more than 100 responses. In addition, the study explores what users expect from the GIS technologies and also provides some insight into the current status of 3D data, paying particular attention to CityGML, given its relevance as an open standard tailored to the urban scale and its related applications.

\section{BACKGROUND}

\subsection{D \& 3D GIS: Where are we heading?}

Starting from the early 90s, GIS has become a sophisticated system for maintaining and analysing geospatial data. 2D GIS has been around for quite some time now and there are a multitude of known applications ranging from transportation planning, engineering and operating (Ziliaskopoulos, Waller), epidemiology (Yang et al., 2005), water-resources planning (McKinney et al., 1993), emergency management (Newsom, Mitrani), business planning (Mennecke, 1997), and urban and regional planning (Yeh, 1991), among many others.

The need for $3 \mathrm{D}$ information is rapidly increasing. The modelling that we were able to conduct so far in $2 \mathrm{D}$ did not take into account the third dimension. For instance, a 2D flood simulation only provides us with the geographic locations that are potentially affected by the floods. From this data we cannot determine which floors of the buildings are affected and under what conditions, etc. Including the the third dimension component built into our models can really change this situation. The use of $3 \mathrm{D}$ city models in performing such simulations has considerably increased in the recent years. There are various application in the realm of 3D city models, these range from visibility analysis, emergency response, solar potential estimation and noise propagation to name a few, Biljecki et al. (2015) have a comprehensive overview of applications. Furthermore, several major cities around the globe such as New York, Amsterdam, Berlin are using 3D city models for different applications.

GIS software and tools have also made a significant movement towards 3D. A survey conducted by Leskens et al. (2017) showed that $3 \mathrm{D}$ visualisations have an enormous added value over 2D. A number of GIS standards and other formats have been developed to aid the representation and processing of these models such as CityGML (OGC, 2012) and CityJSON (Ledoux et al., 2019). Furthermore, database solutions such as 3D City Database $^{1}$ have been developed for the management of these

${ }^{1}$ https://www.3dcitydb.org

\footnotetext{
* Corresponding author
} 
models. A multitude of other open 3D formats also exists for visualizing the 3D data in a web browser such as COLLADA ${ }^{2}$, $\mathrm{KML}^{3}, \mathrm{gITF}^{4}$. With the advancements in the development of 3D web based applications, virtual globes have emerged as a new medium for visualising and interacting with geodata including 3D data e.g. Cesium 3D webglobe ${ }^{5}$. As technologies continue to progress, we should see 3D city models become more and more affordable, thus allowing a faster transition to 3D GIS.

\section{METHODOLOGY}

\subsection{Survey design}

A web-based survey, utilising Google forms, was designed to investigate the adoption of GIS data, standards, and software by the practitioners. The full survey can be accessed here: https://forms.gle/Bvuej46gXNe4oufL9. The survey was distributed via Twitter and LinkedIn.

Participants were asked a number of questions within the following categories:

1. Awareness about the various GIS standards

2. Popular choices in the GIS community: GIS data, standards/formats, and software

3. Attitude towards 3D GIS and CityGML

4. User expectations from the GIS technologies

\subsection{Participants}

The main target group of the survey were researchers and professionals who work directly and indirectly with geoinformation. The web-based survey was distributed within the authors' personal networks and via social media (Twitter, LinkedIn). Adequate measures were taken to ensure the confidentiality of the participants' responses. A total of 101 responses were received from 21 countries ranging across South America, North America, Europe, Asia and Oceania. Respondents came from a variety of fields including academia, government, architecture, surveying, spatial planning, environment management, etc. (Figure 1).

\subsection{Data analysis}

The data analysis was carried out using Python version 3.7 and $R$ version 3.5.0.

\section{RESULTS}

A visual analysis of responses to the main questions is included in the Appendix Section. This section summarises the main findings.

\subsection{Summary of Survey Results}

More than $90 \%$ of the participants have an understanding of the GIS standards (e.g. OGC, ISO standards) and find them useful for their work. The vast majority of respondents worked with $2 \mathrm{D}$ vector data $(92.2 \%)$, while $2.5 \mathrm{D}$ vector data was the least utilised with only $60 \%$ of respondents.

\footnotetext{
${ }^{2}$ https://www.khronos.org/collada/

${ }^{3}$ https://developers.google.com $/ \mathrm{kml} /$

${ }^{4}$ https://www.khronos.org/gltf/

${ }^{5}$ https://cesiumjs.org
}

Shapefile continued its de facto reign over the 2D GIS formats realm $(94.5 \%)$ but GeoTIFF $(90.1 \%)$ and GeoJSON $(75.8 \%)$ are also two strong formats being utilised. The $3 \mathrm{D}$ realm saw lower usage than the $2 \mathrm{D}$ realm, with the most utilised format, KML, coming in at only $66.7 \%$ followed by CityGML at $55.2 \%$. QGIS is the most used GIS software at $88.9 \%$ while ArcGIS trailed behind at $55.6 \%$, and when it comes to ETL (Extract, Transform and Load) tools, FME at 33.3\%. For other software many participants suggested scripting languages such as $R$ and Python. In the database realm $84.8 \%$ utilised spatial databases, with PostgreSQL/PostGIS being the overwhelming majority at $93.5 \%$.

We intentionally did not include BIM and other computer graphics standard in this survey, as the major goal of this inquiry was the usage of GIS at the urban scale. Therefore, in the last part of the survey, we focussed our study to the popular 3D urban GIS standard CityGML and which levels of detail (LODs) most users utilised. 87\% of respondents were familiar with the standard CityGML, and of them, 56.8\% utilised LOD1 models and $55.4 \%$ utilised LOD2 models, those 2 being the most popular LODs.

$72.2 \%$ of respondents planned to use 3D data and standards in the next 2 years. The top applications for use were city planning $(61 \%)$, infrastructure management $(45.5 \%)$, flood mapping $(41.6 \%)$ and energy $(36.4 \%)$. Respondents were also offered the opportunity to add further applications and this generated an interesting list (in bold are applications suggested by the survey):

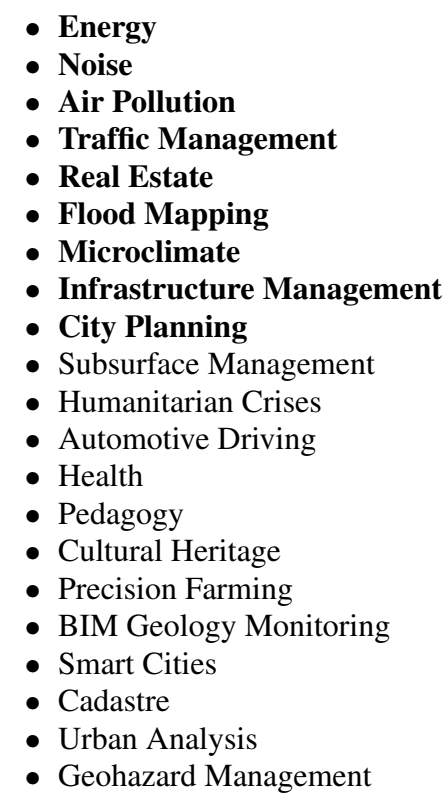

\subsection{Participant Opinions and Expectations}

The last part of the survey asked the open question: "[What is] Your opinion/expectations from 2D/3D GIS technologies?" This generated some interesting responses with the most common themes summarised as follows:

- There is a need for increased software support for 3D GIS, specifically open source solutions

- Further harmonisation between 3D GIS standards is necessary 


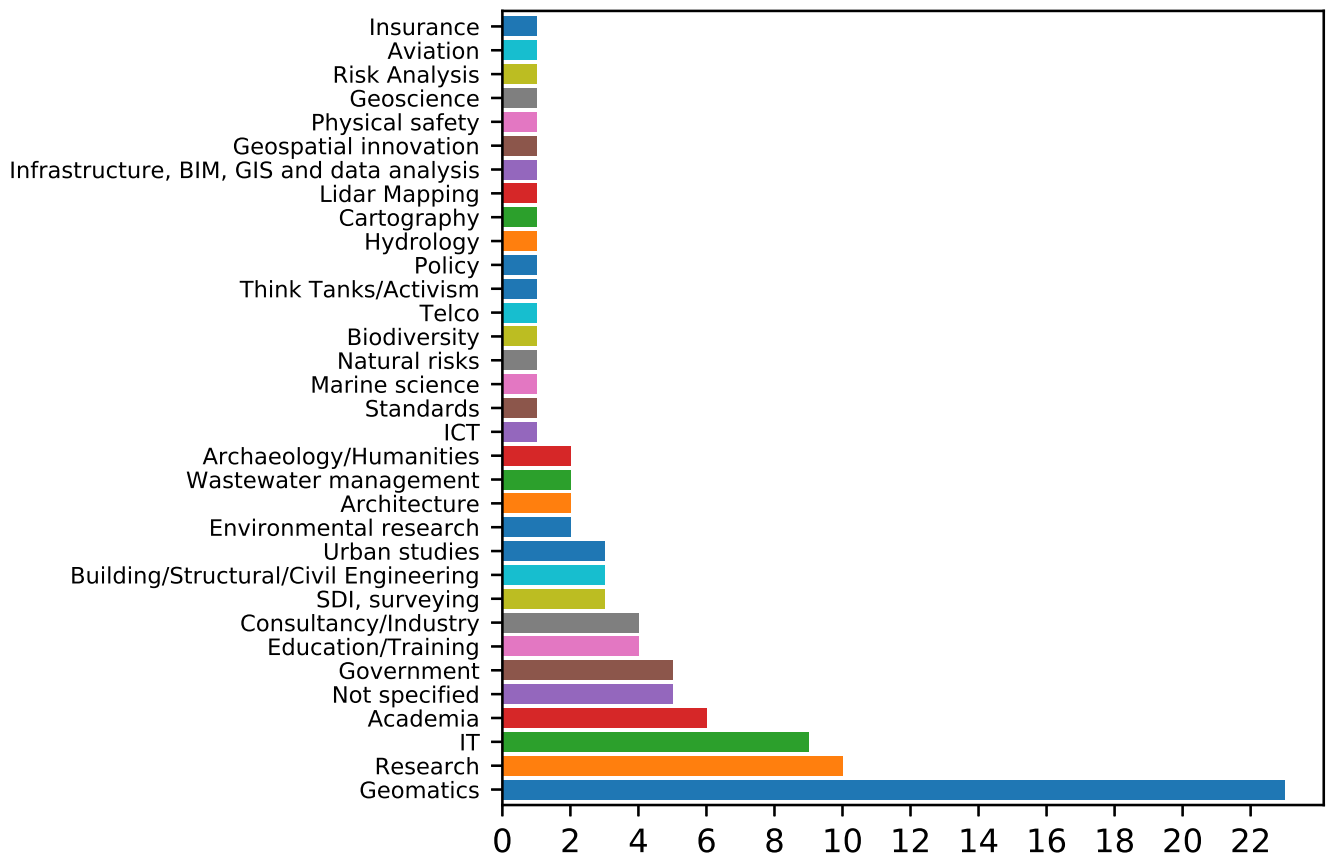

Figure 1. Distribution of the field/area of work of the participants (by percentage).

- An increased awareness of the added value of 3D GIS and its applications would be helpful, especially for those in the predominantly $2 \mathrm{D}$ dominated domains

- More interoperability between the GIS and BIM worlds

- Higher availability of open data

- There is an interesting split between respondents saying that 3D GIS is the future and those that question its need altogether

Some samples of the opinions provided by the anonymous participants are:

"Still lots to do in terms of software availability (and usability) regarding 3D, but lots has been done in the past (recent years). So I am optimistically looking at the future for a new "Copernican revolution" from $2 D$ to $3 D$. I am aware that for some specific applications, 3D may indeed be an overshoot, however I strongly believe that some (so far) predominantly $2 D$ dominated domains (urban planning, etc.) still need to understand the added value of $3 D$. Once this happens, there will be a major drive to foster further development of $3 D$-aware tools. AS a matter of fact, the world is not so much $2 D$ as many keep believing..."

"Open / public data has started to get used more and more by various parties. This changes the playing field and creates the need for the data providers to operationalize data access on enterprise scale with security, scalability and SLAs [Service-level agreements]. Nice to see that lots of efforts finally pay off and turn into live data usage."

"I expect that the worlds of GIS, 3D design and the integration of other information sources will slowly move towards each other. Future developments will focus on (standardized) frameworks which allow an easy integration and enrichment of data, but also an integration of platforms, apps and functionality. This can only be done with standards."

\section{CONCLUSION}

The results of the survey demonstrate a clear trend towards the increased use of GIS in a number of application domains including architecture, geosciences, hydrology, and so on. More than $90 \%$ of the participants found GIS standards useful for their work. This is probably due to the high provision of opportunities to develop GIS competencies in the organizations.

The popular choice of GIS software turned out to be QGIS, which reflects, on one hand, the increased popularity of the open-source packages in GIS, but on the other calls for a better support for 3D from the FOSS (Free and Open Source Software) community. Another interesting finding around software is the number of people that suggested utilising a combination of $R$ and Python. Open data was also a popular choice with $92.3 \%$ of respondents reporting to work with it. Over-all a clear trend towards open software and open data is evident.

There are some potential limitations to this survey that should be addressed for future iterations of this work. The results are potentially skewed to the $3 \mathrm{D}$ world given that our networks consist of many 3D GIS users. Additionally, in the future it would be beneficial to survey non-GIS users about potential future applications and use cases to better understand their needs and explore new opportunities.

To conclude, when developing an application framework nowadays, GIS standards play a steadily growing role and cannot be neglected anymore. There still exist a number of issues that can impede or hinder data interoperability. However, an encouraging result of the survey is that it is becoming more and more widely accepted that one way to solve or minimize the impact of such issues is the adoption of standards, especially when dealing with the urban scale, as the number of ("smart") applications consuming heterogeneous data is continuously growing. Furthermore, understanding the current applications 
of 3D city models can assist in creating the necessary software support.

\section{ACKNOWLEDGEMENTS}

The research leading to this paper is a part of the research project 3D4EM (3D for Environmental Modelling) in the Maps4Society programme (Grant Number 13740) which is funded by the NWO (Netherlands Organisation for Scientific Research), and partly funded by the Ministry of Economic Affairs. This work is also funded by the European Research Council under the European Union's Horizon 2020 ERC Agreement no. 677312 UMnD: Urban modelling in higher dimensions.

\section{REFERENCES}

Biljecki, F., Stoter, J., Ledoux, H., Zlatanova, S., Çöltekin, A., 2015. Applications of 3D City Models: State of the Art Review. ISPRS International Journal of Geo-Information, 4(4), 2842-2889.

Bissette, J. M., Stover, J. A., Newman, L. M., Delcher, P. C., Bernstein, K. T., Matthews, L., 2009. Assessment of geographic information systems and data confidentiality guidelines in STD programs. Public Health Reports, 124(2_suppl), 58-64.

De Roo, B., Bourgeois, J., De Maeyer, P., 2013. A survey on the use of GIS and data standards in archaeology. International Journal of Heritage in the Digital Era, 2(4), 491-507.

Göçmen, A. Z., Ventura, S. J., , 2010. Barriers to GIS use in planning. Journal of the American Planning Association, 76(2), 172-183.

Kerski, J., 1999. A nationwide analysis of the implementation of gis in high school education. Proceedings of the 21 st Annual ESRI User Conference, San Diego, California.

Ledoux, H., Arroyo Ohori, K., Kumar, K., Dukai, B., Labetski, A., Vitalis, S., 2019. CityJSON: A compact and easy-to-use encoding of the CityGML data model. Open Geospatial Data, Software and Standards. (Accepted for publication).

Leskens, J. G., Kehl, C., Tutenel, T., Kol, T., De Haan, G., Stelling, G., Eisemann, E., 2017. An interactive simulation and visualization tool for flood analysis usable for practitioners. Mitigation and adaptation strategies for global change, 22(2), 307-324.

McKinney, D. C., Maidment, D. R., Tanriverdi, M., 1993. Expert geographic information system for Texas water planning. Journal of Water Resources Planning and Management, 119(2), 170-183.

Mennecke, B. E., 1997. Understanding the role of geographic information technologies in business: Applications and research directions. Journal of Geographic Information and Decision Analysis, 1(1), 44-68.

Newsom, D. E., Mitrani, J. E., 1993. Geographic information system applications in emergency management. Journal of Contingencies and Crisis Management, 1(4), 199-202.

OGC, 2012. OGC City Geography Markup Language (CityGML) Encoding Standard 2.0.0. Doc. No. 12019. https://portal .opengeospatial.org/files/

?artifact_id $=47842$.
Wong, K. K. Y., 2015. Economic value of 3D geographic information. EuroSDR and the Department of Computer Science, University College London: London, UK.

Yang, G.-J., Vounatsou, P., Xiao-Nong, Z., Utzinger, J., Tanner, M., 2005. A review of geographic information system and remote sensing with applications to the epidemiology and control of schistosomiasis in China. Acta tropica, 96(2-3), 117-129.

Yeh, A. G.-o., 1991. The development and applications of geographic information systems for urban and regional planning in the developing countries. International journal of geographical information system, 5(1), 5-27.

Ziliaskopoulos, A. K., Waller, S. T., 2000. An Internet-based geographic information system that integrates data, models and users for transportation applications. Transportation Research Part C: Emerging Technologies, 8(1-6), 427-444. 


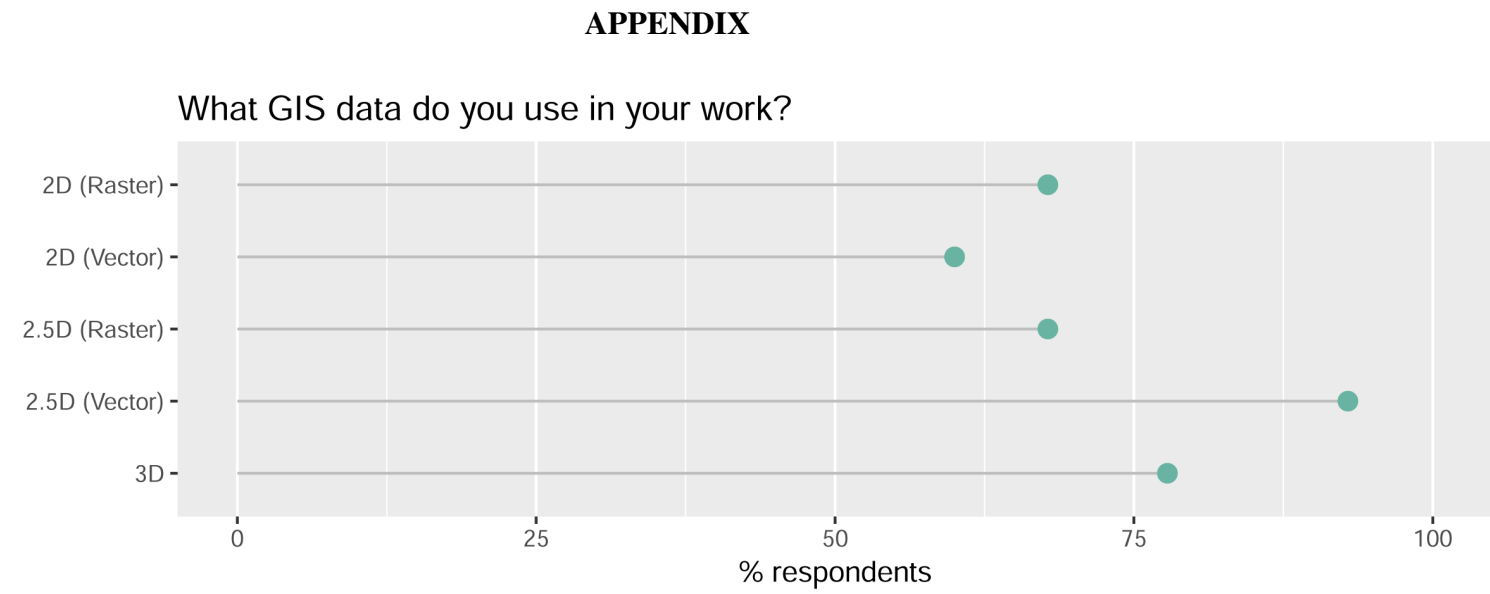

Which 2D GIS formats have you used?

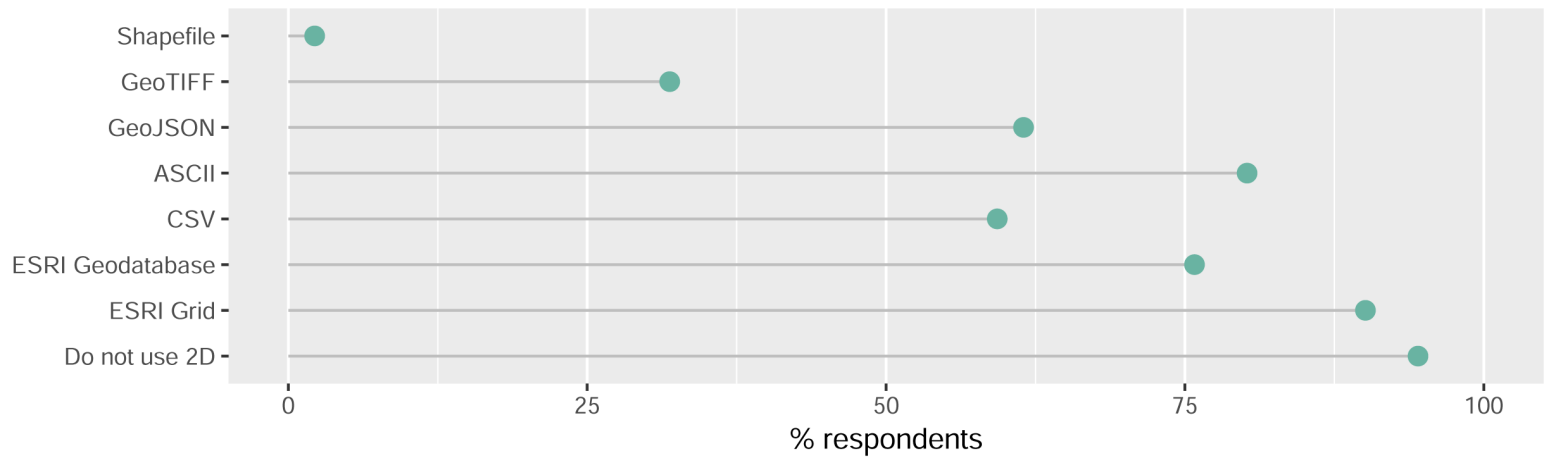

Which 3D GIS formats have you used?

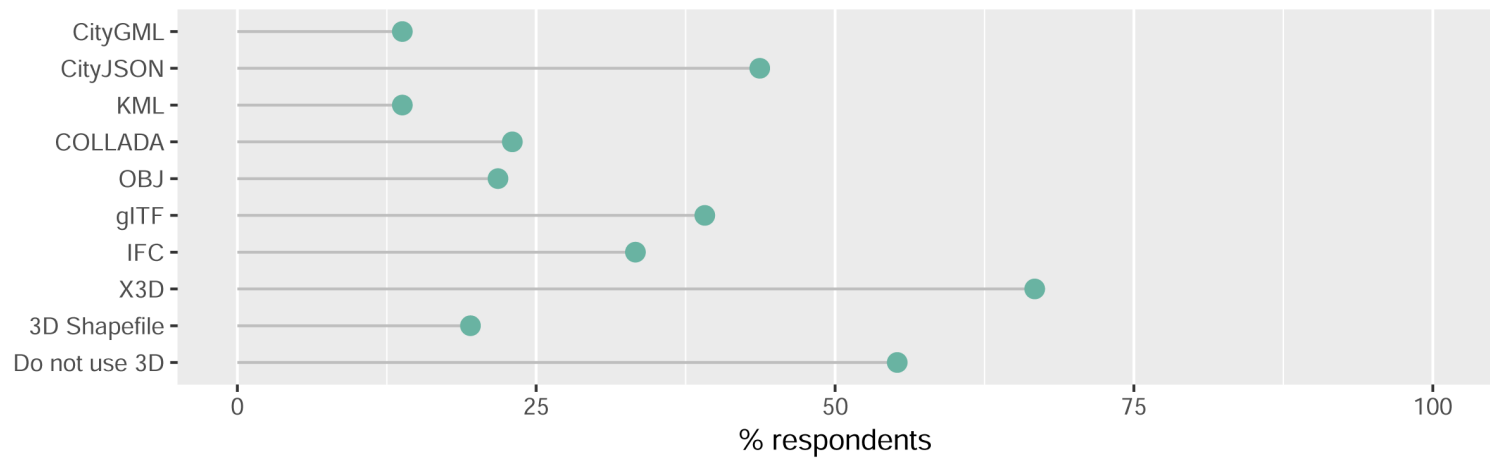

Which software do you frequently use for GIS?

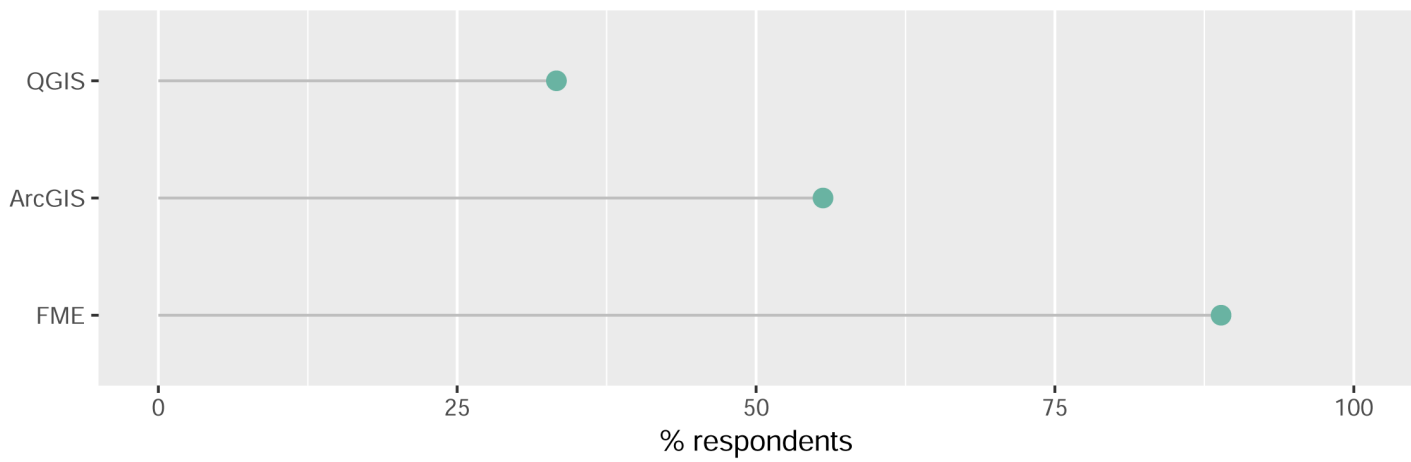


Which database management system do you use?

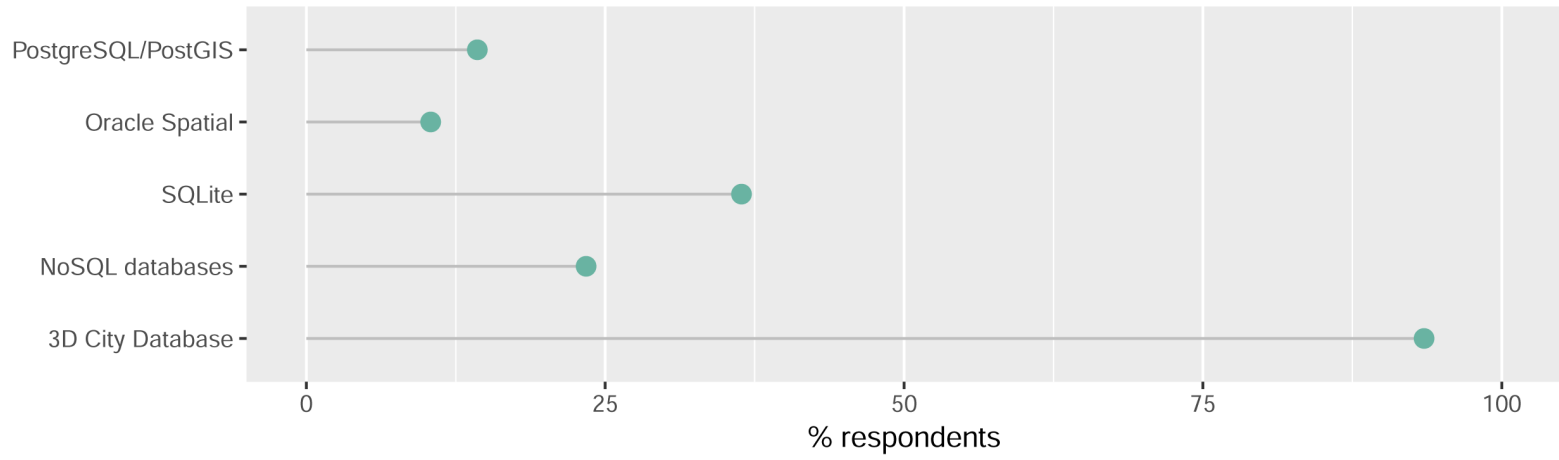

Which LOD (Level of Detail) of CityGML have you used?

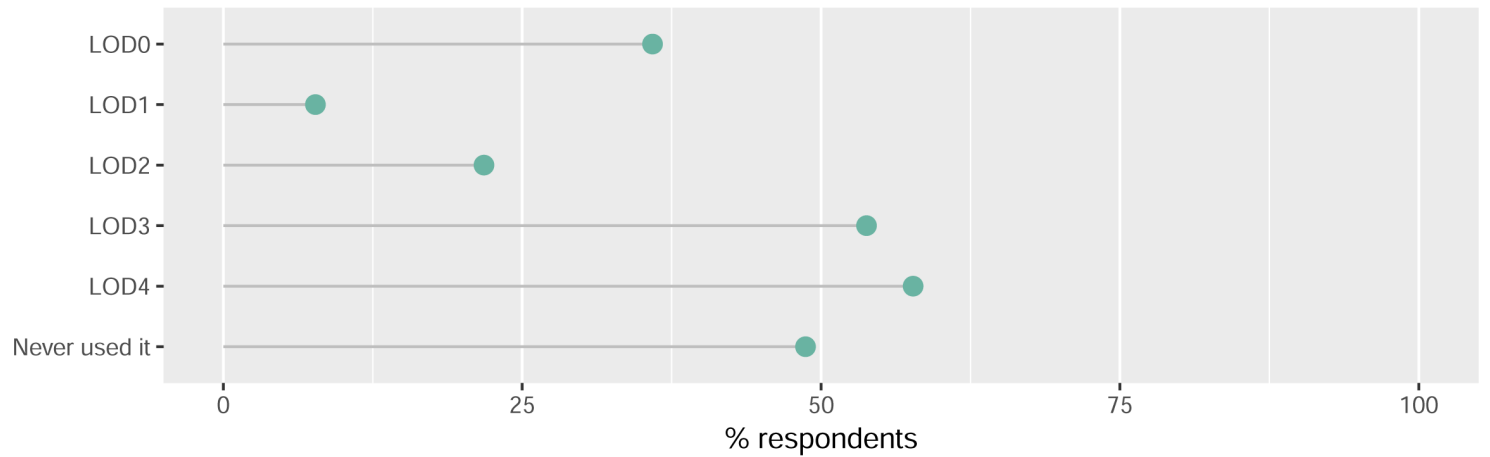

For which application would you use 3D city data in the next 2 years?

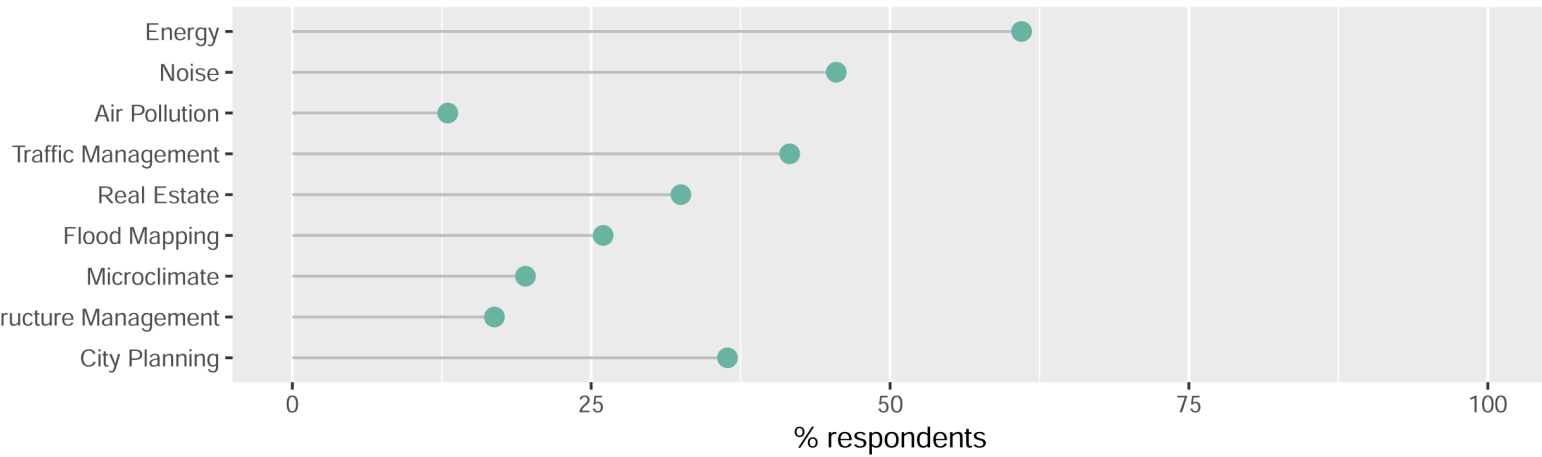

How would you describe the GIS data that you use in your research/work?

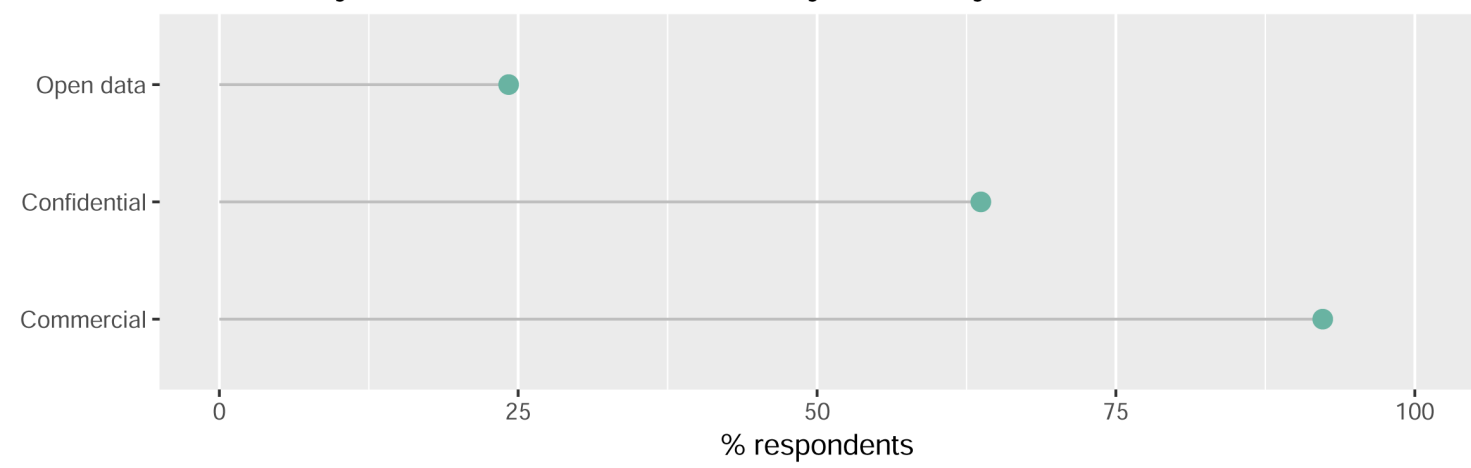

